\title{
Proceeding
}

Supplementary Issue: Autumn Conferences of Sports Science. Costa Blanca Sports Science Events, 18-19 December 2020. Alicante, Spain.

\section{Calcific tendinopathy of supraspinatus tendon in elite volleball players: A point-of-care ultrasound diagnosis}

\author{
ANTONIO CORVINO ${ }^{1} \triangle$, FABIO CORVINO², ALESSANDRO LICCARDO ${ }^{1}$, DOMENICO TAFURI ${ }^{1}$ \\ ${ }^{1}$ Motor Science and Wellness Department, University of Naples "Parthenope", Naples, Italy \\ ${ }^{2}$ Vascular and Interventional Radiology Department, Cardarelli Hospital, Naples, Italy
}

\begin{abstract}
In overhead sports like volleyball, the onset of a rotator cuff tendinopathy due to functional overload is a not uncommon observation. Herein, we present the case of a symptomatic calcific tendinopathy involving the supraspinatus tendon with a subacromial impingement syndrome in a young elite volleyball player. Shoulder and supraspinatus tendon evaluation with static and dynamic ultrasonography (US) can assist in the rapid diagnosis of tendinopathy. Thus, sports physicians must be aware of this in order to expedite rapid referral to a musculoskeletal specialist who can perform a point-of-care US examination of the shoulder. This approach to sports pathology potentially improves patient outcomes.

Keywords: Overhead athletes; Shoulder pain; Calcific tendinopathy; Shoulder impingement; Ultrasound.

Cite this article as:

Corvino, A., Corvino, F., Liccardo, A., \& Tafuri, D. (2021). Shoulder impingement in overhead athletes: An uncommon complication of distal clavicle fracture. Journal of Human Sport and Exercise, 16(2proc), S252-S258. doi:https://doi.org/10.14198/jhse.2021.16.Proc2.10
\end{abstract}

Corresponding author. Motor Science and Wellness Department, University of Naples "Parthenope", Naples, Italy.

E-mail: antonio.corvino@uniparthenope.it

Abstract submitted to: Autumn Conferences of Sports Science. Costa Blanca Sports Science Events, 18-19 December 2020. Alicante, Spain.

JOURNAL OF HUMAN SPORT \& EXERCISE ISSN 1988-5202

(c) Faculty of Education. University of Alicante

doi:10.14198/jhse.2021.16.Proc2.10

S252 | 2021| Proc2 | VOLUME 16

C 2021 University of Alicante 


\section{INTRODUCTION}

Volleyball is one of the most popular sports in the world, played by more than 200 million athletes worldwide (Raiola, Tafuri \& Paloma, 2014; Raiola, Tafuri \& Altavilla, 2015; Raiola \& Tafuri, 2015). It was first introduced in 1895 by an American physical training teacher, William G. Morgan, as a recreational activity for students at college in the USA, and its popularity spread rapidly. It is a non-contact sport, since the players in the opposite teams are separated by a net, so the incidence of injury is relatively low. However, it demands rapid movements to change the body position in space, in the horizontal, vertical and rotational directions, and the arms undergo the greatest strain during overhead movements, as they do in other sports activities like baseball, tennis, basketball, and swimming, in which degenerative diseases of the rotator cuffs are also common (Notarnicola A et al., 2012; Raiola, Lipoma \& Tafuri, 2015).

In clinical practice, rotator cuff (RC) tendon calcifications are by no means a rarity; they are in fact one of the most common shoulder abnormalities (Figure 1). They are known to be self-limiting, running an asymptomatic course in up to $50 \%$. However, in those patients who have associated shoulder pain, a painful restriction in range of motion and limitations in activities of daily living are reported (Merolla $\mathrm{G}$ et al., 2016).

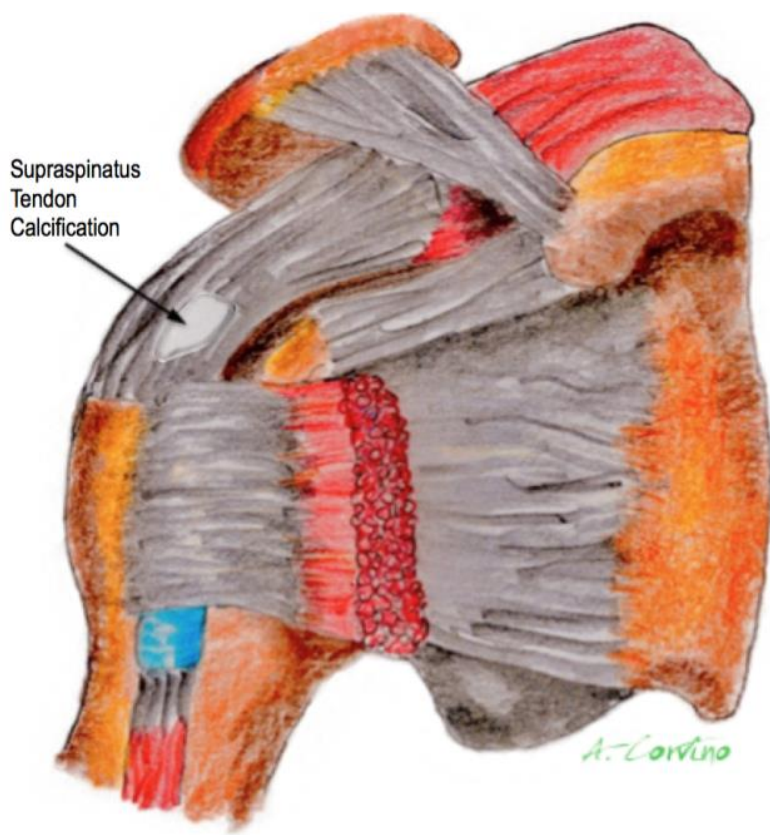

Figure 1. Coronal 3D colour perspective of the calcium deposition within the substance of the supraspinatus tendon.

Diagnostic ultrasound (US) evaluation of supraspinatus tendon calcifications with subacromial impingement syndrome has been reported to be specific (95\% to $96 \%)$ and sensitive $(71 \%$ to $81 \%)$ in adult patients, and supraspinatus tendon calcifications with subacromial impingement syndrome diagnosed through US has been reported in young athletes who perform overhead sports (Corvino et al., 2020). Thus, sports physicians must be aware of this in order to expedite rapid referral to a musculoskeletal specialist who can perform a point-of-care US examination of the shoulder.

Herein, we present a case of symptomatic calcific tendinopathy (CT) involving the supraspinatus tendon with subacromial impingement syndrome in a young elite volleyball player. 


\section{Case presentation}

A 23-year-old elite volleyball player was referred to our hospital with progressively worsening right shoulder pain over six months. The pain was aggravated with sport activity and decreased the sleep quality. He had been an elite volleyball player for approximately 15 years before the onset of his symptoms. He typically trained three times a week and played at least one match per week.

Aside from the pain on her right shoulder, the patient reported no associated trauma, right upper-extremity numbness or tingling, shortness of breath, chest pain, or fever. Laboratory blood tests revealed no abnormalities. Blood pressure was $120 / 70 \mathrm{mmHg}$ and heart rate $85 \mathrm{bpm}$. The patient's electrocardiogram showed a normal sinus rhythm with no ST or T-wave abnormalities.

On physical examination, there was pain over the lateral part of his right shoulder near the tendinous insertion of the supraspinatus muscle, especially when the patient elevating and abducting the right arm. Both passive and active movements of his shoulder were almost completely restricted due to the severe pain. The right arm was neurovascularly intact with normal motor and sensory functions of radial, median, ulnar, and axillary nerves.

On initial assessment, the sport physician considering the severe pain that the patient was experiencing and suspecting possible shoulder CT, facilitated rapid pain medication administration and a rapid US evaluation of the patient's right shoulder. Thus, a focused point-of-care ultrasound examination of the patient's shoulder was performed. With the patient in modified Crass position, where the patient placed her palm on her ipsilateral iliac wing and moved her elbow as posterior as possible, long-axis evaluation of the patient's supraspinatus tendon revealed a globular calcification near the attachment to the greater tuberosity of the humerus (Figure 2). The verification of the calcification was done by plain radiographs (Figure 3).

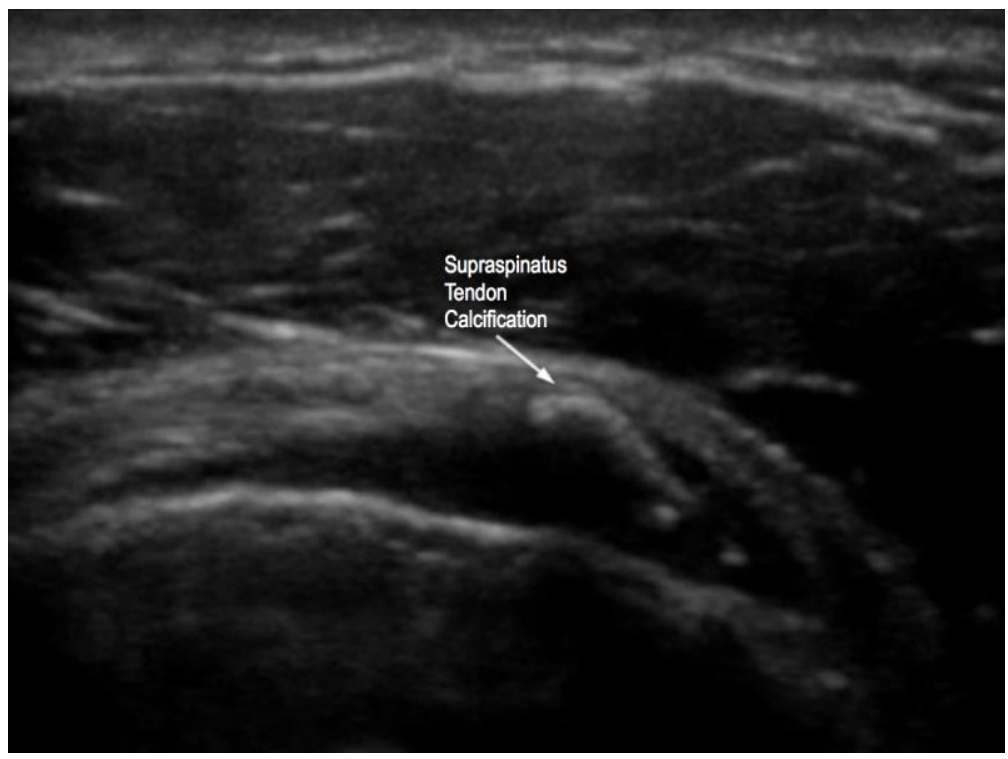

Figure 2. US long axis scan of supraspinatus tendon showing an arc-shaped calcification near the attachment to the greater tuberosity of the humerus.

For the patient, treatment began on her first visit with a subacromial corticosteroid injection. The injection contained $0.5 \%$ bupivacaine with $40 \mathrm{mg} / \mathrm{mL}$ of methylprednisolone. He reported significant pain relief within 
10 minutes of receiving the injection and was able to abduct his shoulder to $70-80^{\circ}$. We scheduled the patient for two additional injections over the next 60 days. In follow-up radiographs taken after two injections, there was almost complete resolution of the condition. At the time of this writing, it has been 6 weeks since the patient's last visit and he is pain-free, with full motion of his shoulder.

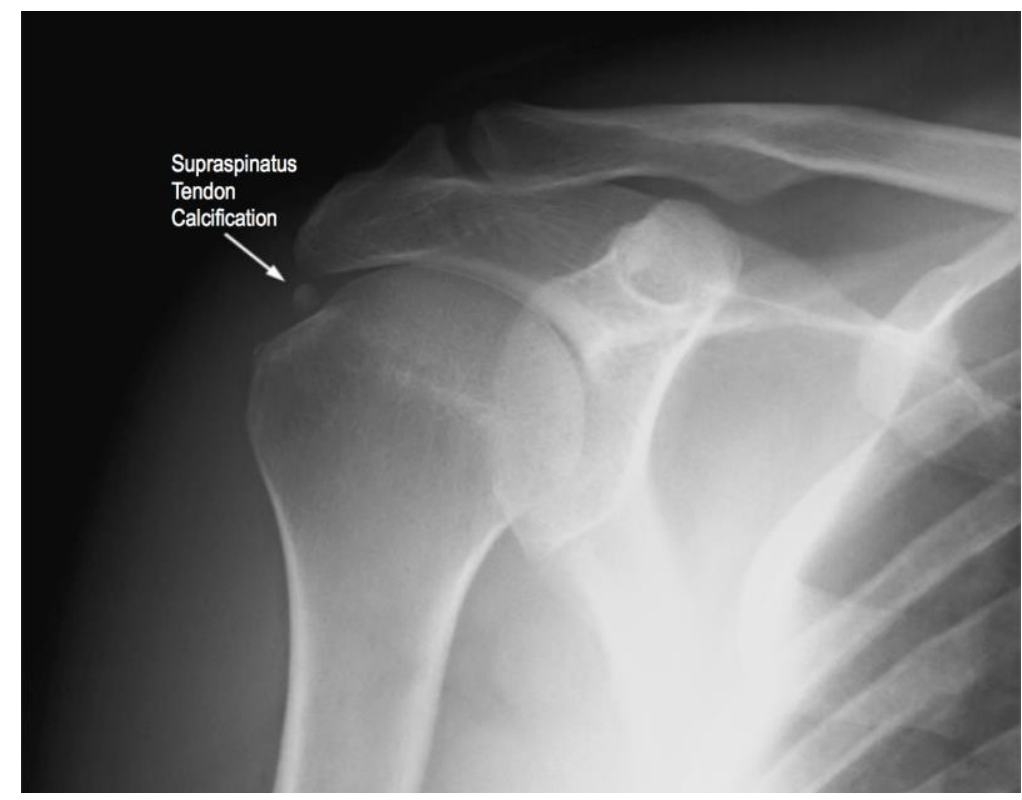

Figure 3. Standard radiograph (antero-posterior view) confirms the supraspinatus tendon CT.

\section{DISCUSSION}

RCCT is a very common condition due to the presence of calcific deposits inside or around the tendons of the RC. More specifically, it is caused by the deposition of calcium hydroxyapatite crystals commonly within the supraspinatus and infraspinatus tendons. Intratendinous calcifications can be found in up to $7.5 \%$ of asymptomatic shoulders and in up to $20 \%$ of painful shoulders. When symptomatic, CT can be very painful and disabling for patients, thus requiring prompt treatment (Sansone $V$ et al., 2016).

In 1907, Painter was the first to describe the radiographic findings in patients with CT. Codman, in the 1930s, proposed that degeneration of tendon fibres preceded calcifications. In 1902, Harrington and Codman performed the first reported operative removal of a calcific deposits. In the 1987, Ellman first described the arthroscopic removal of calcific deposits. More recently, Uhthoff and Loehr proposed a progressive reactive calcification process to describe the disease (Oliva F et al., 2011).

Although has been discussed, the incidence of this disease is higher either in individuals who do heavy duty work involving the upper limb, or in overhead athletes such as volleyball players. Specifically, Monteleone et al. reported that a RCCT in professional volleyball players was identified ultrasonographically in $30 \%$ of the athletes, a prevalence greater than that reported in the general population (Monteleone $\mathrm{G}$ et al., 2015).

There are studies that hypothesize a multifactorial pathogenesis with overuse and inflammation as primus movens as far as the causes of CT is concerned. Under unfavourable biomechanics situations, recurring movements would cause inflammation and repeating such activities would start a vicious cycle. The 
inflammation would then be structured as calcium crystals. Then, supraspinatus tendon calcifications may lead to bursal inflammation and tendon thickening which could lead to impingement under the acromion of the scapula, causing an impingement syndrome and severe pain, especially upon humerus elevation and abduction (Monteleone $\mathrm{G}$ et al., 2015; Riley DC et al., 2016).

During overhead sport activity, in fact, the soft tissue contents of the subacromial space including the tendons of the rotator cuff must pass under the coracoacromial arch for the athlete to elevate the arm at greater than 90. These actions require maximal abduction with external rotation. Thus, the subacromial bursa and RC tendons are subjected to wear below the coracoacromial arch as the arm accelerates forward. The bursa is a reactive tissue, and this external mechanical stimulus may initiate a response of inflammatory factors, leading to shoulder pain. Our case had repeated repetitive overuse activities (Corvino A et al., 2019).

Dr. Charles Neer in 1972 was the first person to describe subacromial impingement syndrome as a distinct clinical problem. Neer described three stages of subacromial impingement: stage I impingement involves edema and haemorrhage of the subacromial bursa and rotator cuff; stage II impingement involves tendinopathy, such as tendinosis and CT; and stage III impingement involves surgical problems such as a rotator cuff tear (Riley DC et al., 2016; Catalano 0 et al., 2019).

Bigliani and Levine (Riley DC et al., 2016) have classified the causes of subacromial impingement syndrome as either extrinsic/extratendinous or intrinsic/intratendinous. Examples of extrinsic primary impingement include thickening of the coracoacromial ligament and a hook-shaped acromial scapular bone because a hook-shaped acromial bone is more likely to be present in patients with subacromial impingement syndrome and with patients with rotator cuff tears compared to patients who have a flat- or curve- shaped acromial bone. Examples of intrinsic primary impingement are degenerative tendinopathy and supraspinatus tendon calcifications that can lead to tendon thickening and impingement, the etiology of our patient's supraspinatus tendon subacromial impingement and shoulder pain.

US examination is a fundamental tool in diagnosis and treatment of CT. Use of high-resolution US shows the presence of deposits and also defines their locations in the tendons, plus their size and texture. This technique enables staging of the deposits by correlation of shadow cones and also shows RC tears in detail. More recently, US has changed from having a purely diagnostic role to become an important therapeutic tool, especially for carrying out bursal lavage and tendon needling (Panzetta et al, 2017; Sandomenico F et al., 2019). Radiologists have developed a full five-step US shoulder protocol that includes evaluation of the following structures: the long head of the biceps brachii tendon, the subscapularis tendon, the supraspinatus tendon and rotator interval with both static and dynamic evaluation for subacromial impingement, the acromio-clavicular joint, and the infraspinatus and teres minor tendons with the posterior glenoid labrum (De Carli A et al., 2014). In this setting, US has proved to be $79 \%$ sensitive and $88 \%$ specific for diagnosing supraspinatus tendon calcifications and impingement syndrome using dynamic manoeuvres (Riley DC et al., 2016).

In our case, a focused point-of-care US examination of the shoulder was performed, and this revealed a calcification near the attachment to the greater tuberosity of the humerus and impingement of the supraspinatus tendon underneath the acromion of the scapula, especially when the patient actively elevated and abducted the humerus. Thus, shoulder US examination can help in preventing missed or delayed diagnosis of supraspinatus tendon calcifications with subacromial impingement syndrome when the diagnosis is not always clear clinically or physical examination manoeuvres can be limited by pain and soft tissue swelling. 


\section{CONCLUSION}

Shoulder and supraspinatus tendon evaluation with static and dynamic US can assist in the rapid diagnosis of CT. Sports physicians must be aware of this in order to expedite rapid referral to a musculoskeletal specialist who can perform a point-of-care US examination of the shoulder. This approach to sports pathology potentially improves patient outcomes.

\section{REFERENCES}

Catalano O, Alfageme FR, Varelli C, Bard R, Corvino A, Wortsman X. Skin cancer. Findings and role of high-resolution ultrasound. J Ultrasound, 2019; 22(4): 423-431. https://doi.org/10.1007/s40477-01900379-0

Corvino A, Sandomenico F, Corvino F, Campanino MR, Verde F, Giurazza F, Tafuri D, Catalano O. Utility of a gel stand-off pad in the detection of Doppler signal on focal nodular lesions of skin. J Ultrasound, 2020; 23(1):45-53. https://doi.org/10.1007/s40477-019-00376-3

Corvino A, Rosa D, Sbordone C, Nunziata A, Corvino F, Varelli C, Catalano O. Diastasis of rectus abdominis muscles: patterns of anatomical variation as demonstrated by ultrasound. Pol J Radiol, 2019; 84:e542-e548. https://doi.org/10.5114/pjr.2019.91303

De Carli A, Pulcinelli F, Rose GD, Pitino D, Ferretti A. Calcific tendinitis of the shoulder. Joints, 2014; 2(3):130-6. https://doi.org/10.11138/jts/2014.2.3.130

Merolla G, Singh S, Paladini P, Porcellini G. Calcific tendinitis of the rotator cuff: state of the art in diagnosis and treatment. J Orthop Traumatol, 2016; 17(1):7-14. https://doi.org/10.1007/s10195-015$\underline{0367-6}$

Monteleone G, Tramontana A, Mc Donald K, Sorge R, Tiloca A, Foti C. Ultrasonographic evaluation of the shoulder in elite Italian beach volleyball players. J Sports Med Phys Fitness, 2015; 55(10):11939. Epub 2014 May 27. PMID: 24867605.

Notarnicola A, Fischetti F, Gallone D, Moretti L, Pignataro P, Tafuri S, Moretti B. Overload and neovascularization of shoulder tendons in volleyball players. BMC Res Notes, 2012; 5:397. https://doi.org/10.1186/1756-0500-5-397

Oliva F, Via AG, Maffulli N. Calcific tendinopathy of the rotator cuff tendons. Sports Med Arthrosc Rev, 2011; 19(3):237-43. https://doi.org/10.1097/JSA.0b013e318225bc5f

Panzetta, V., De Menna, M., Musella, I., Pugliese, M., Quarto, M., Netti, P. A., \& Fusco, S. (2017). Xrays effects on cytoskeleton mechanics of healthy and tumor cells. Cytoskeleton, 74(1), 40-52. https://doi.org/10.1002/cm.21334

Raiola, G., Lipoma, M., \& Tafuri, D. (2015). Postural control in young soccer players: differences between the cognitive approach and ecological-dynamic one. Journal of Human Sport and Exercise, 10(Special Issue), pp. S385-S390. https://doi.org/10.14198/jhse.2015.10.Proc1.29

Raiola, G., Tafuri, D., Paloma, G. (2014). Physical activity and sport skills and its relation to mind theory on motor control. Sport Science, 7(1), pp. 53-57.

Raiola, G., Tafuri, D., Altavilla, G. (2015). Physical activity and its relation to body and ludic expression in childhood. Mediterranean Journal of Social Sciences, 6(3), pp. 293-296.

Raiola, G., Tafuri, D. (2015).Teaching method of physical education and sports by prescriptive or heuristic learning. Journal of Human Sport and Exercise, 10(Specialissue), pp. S377-S384. https://doi.org/10.14198/ihse.2015.10.Proc1.28

Riley DC, Kaufman M, Ward TM, Acevedo Y, Guerra R, Folorunsho A. Emergency department diagnosis of supraspinatus tendon calcification and shoulder impingement syndrome using bedside ultrasonography. Crit Ultrasound J, 2013; 5(1):2. https://doi.org/10.1186/2036-7902-5-2 
Sandomenico F, Corvino A, Ronza FM, Catalano O, Fazioli F, De Chiara A, Campanino MR, Porcaro M, Tafuri D, Petrillo A. Recurrence of tumoral calcinosis: a case report. Acta Biomed, 2019; 90(4):587594. https://doi.org/10.23750/abm.v90i4.8251

Sansone V, Consonni O, Maiorano E, Meroni R, Goddi A. Calcific tendinopathy of the rotator cuff: the correlation between pain and imaging features in symptomatic and asymptomatic female shoulders. Skeletal Radiol, 2016; 45(1):49-55. https://doi.org/10.1007/s00256-015-2240-3

\section{@() $\Theta \Theta \Theta$}

This work is licensed under a Attribution-NonCommercial-NoDerivatives 4.0 International (CC BY-NC-ND 4.0). 